\title{
A INFÂNCIA NA CONCEPÇÃO DE EDUCADORES SOCIAIS QUE TRABALHAM EM INSTITUIÇÕES DE ACOLHIMENTO EM PONTA GROSSA
}

\author{
CHILDHOOD IN THE CONCEPTION OF SOCIAL EDUCATORS THAT WORK IN \\ HOST INSTITUTIONS IN PONTA GROSSA
}

\section{LA INFANCIA EN LA CONCEPCIÓN DE EDUCADORES SOCIALES QUE TRABAJAN EN INSTITUCIONES DE ACOGIMIENTO EN PONTA GROSSA}

\author{
Gládis Goetê Azambuja* \\ Tábata Saionara Cecílio* \\ Érico Ribas Machado ${ }^{* * *+}$
}

\begin{abstract}
Resumo:Este trabalho resulta de uma pesquisa realizada para o trabalho de conclusão do Curso de Pedagogia e compõe uma linha de investigação desenvolvida no Núcleo de Estudos, Pesquisas e Extensão em Pedagogia, Pedagogia Social e Educação Social - NUPEPES registrado no Diretório de Grupos de Pesquisa do $\mathrm{CNPq}$, situado na Universidade Estadual de Ponta Grossa - Paraná. Historicamente crianças e adolescentes aparecem como os primeiros grupos humanos a sofrerem com as crises que a humanidade cria. É interessante identificar que a figura do(a) Educador(a) Social aparece no cenário de práticas educativas em diferentes espaços, justamente no trabalho junto à essas crias e adolescentes. Essa tese levou o NUPEPES a estabelecer essa reflexão com parte dos integrantes do grupo e especificamente nesta pesquisa inspirou as alunas concluintes do Curso de Pedagogia a pensarem sobre a concepção de infância que os(as) Educadores(as) Sociais possuem nos seus espaços de trabalho. Os dados foram coletados nas instituições de instituições de acolhimento - nova denominação para os chamados abrigos, que atendem crianças na cidade de Ponta Grossa - PR. O objetivo da pesquisa foi compreender qual é a concepção do(a) Educador(a) Social sobre a infância a partir dos seus trabalhos nesses espaços também educativos. O procedimento metodológico utilizado para coleta de dados foi a entrevista por meio de um questionário semiestruturado. As discussões teóricas para análise dos dados e fundamentação foram pautadas em autores que desenvolveram conceitos sobre infâncias e crianças. Também foram utilizadas publicações que relacionam as perspectivas da Educação Social - Pedagogia Social com as concepções de infância. Problematizar a existência da infância como sob a perspectiva da Educação Social - Pedagogia Social é compreender que essa infância é determinada por um contexto social e cultural que irá delinear a existência daquele sujeito entendido como ser humano que é chamado de criança. Outra abordagem para reflexão e que inspira essas discussões é compreender que assim como a escola é oficialmente reconhecida como espaço educativo que trabalha, entre outros grupos, com crianças, e existe a defesa da necessidade do preparo qualificado do profissional - professor -
\end{abstract}

\footnotetext{
*Pedagoga formada pela Universidade Estadual de Ponta Grossa. Integrante do Núcleo de Estudos, Pesquisas e Extensão em Pedagogia, Pedagogia Social e Educação Social - NUPEPES. E-mail: ggoete@hotmail.com

** Pedagoga formada pela Universidade Estadual de Ponta Grossa. Integrante do Núcleo de Estudos, Pesquisas e Extensão em Pedagogia, Pedagogia Social e Educação Social - NUPEPES. E-mail: tabatacecilio@gmail.com

*** Professor Doutor Adjunto do Departamento de Educação e do Programa de Pós-Graduação em Educação da Universidade Estadual de Ponta Grossa. Líder do Núcleo de Estudos, Pesquisas e Extensão em Pedagogia, Pedagogia Social e Educação Social - NUPEPES. E-mail: ericormachado@gmail.com
} 
que atua nesse espaço, também existe a defesa de que o (a) educador(a) social também responsável por um processo educativo específico, necessita de formação adequada e condições para efetivar um trabalho educativo com qualidade no seu espaço de atuação profissional. Afinal a infância presente na escola ou na instituição de acolhimento e nos demais espaços educativos deve ser entendida como uma fase de extrema importância para o desenvolvimento humano, devendo ser garantido seus direitos de existência plena de tranquilidade, ludicidade, amorosidade, cuidados, conhecimentos, e demais fatores que influenciam seu desenvolvimento cognitivo e afetivo.

Palavras-chave: Infância. Educação Social. Pedagogia Social.

Abstract: This work results from a research carried out for the conclusion work of the Pedagogy Course and composes a line of research developed in the Nucleus of Studies, Researches and Extension in Pedagogy, Social Pedagogy and Social Education - NUPEPES registered in the Directory of Research Groups of CNPq , located at the State University of Ponta Grossa - Paraná. Historically children and adolescents appear as the first human groups to suffer with the crises that mankind creates. It is interesting to identify that the figure of the Social Educator appears in the scenario of educational practices in different spaces, precisely in the work along to these young and adolescents. This thesis led the NUPEPES to establish this reflection with part of the members of the group and specifically in this research has inspired the final students of the Course of Pedagogy to think about the conception of childhood that the Social Educators have in their workspaces . The data were collected in the institutions of host institutions - a new denomination for the so-called shelters, which serve children in the city of Ponta Grossa - PR. The objective of the research was to understand the conception of the Social Educator about childhood from their work in these educational spaces. The methodological procedure used for data collection was the interview through a semistructured questionnaire. The theoretical discussions for data analysis and foundation were based on authors who developed concepts about childhood and children. Were also used publications relating the perspectives of Social Education - Social Pedagogy with the conceptions of childhood. To problematize the existence of childhood as from the perspective of Social Education - Social Pedagogy is to understand that this childhood is determined by a social and cultural context that will outline the existence of that subject understood as a human being who is called a child. Another approach to reflection that inspires these discussions is to understand that just as the school is officially recognized as an educational space that works, among other groups, with children, and there is a defense of the need for qualified preparation of the professional - teacher - who works in that space , there is also the defense that the social educator is also responsible for a specific educational process, needs adequate training and conditions to carry out an educational work with quality in its area of professional performance. After all, the childhood present at school or at host institution and another educational spaces should be understood as a phase of extreme importance for human development, and its rights of existence must be guaranteed full of tranquility, playfulness, loveliness, knowledge, and other factors that influence their cognitive and affective development.

Keywords: Childhood. Social Education. Social Pedagogy.

Resumen: Este trabajo resulta de una pesquisa realizada para el trabajo de conclusión del Curso de Pedagogía y compone un linaje de investigación desarrollado en el Núcleo de Estudios, Pesquisas y Extensión en Pedagogía, Pedagogía Social y Educación Social - NUPEPES registrado en el Directorio de Grupos de Pesquisa del CNPq, situado en la Universidade Estadual de Ponta Grossa - Paraná. Históricamente niños y adolescentes aparecen como los primeros grupos humanos que sufren con las crisis que la humanidad crea. Es interesante identificar que la figura del(de la) Educador(a) Social aparece en el escenario de prácticas educativas en diferentes espacios, justamente en el trabajo junto a esos niños y adolescentes. Esa tesis llevó el NUPEPES a establecer esa reflexión con parte de los integrantes del grupo y específicamente en esta pesquisa inspiró las alumnas concluyentes del Curso 
de Pedagogía a que piensen sobre la concepción de infancia que los(as) Educadores(as) Sociales poseen en sus espacios de trabajo. Los datos fueron colectados en las instituciones de instituciones de acogimiento - nueva denominación para los llamados abrigos, que atienden niños en la ciudad de Ponta Grossa - PR. El objetivo de la pesquisa fue comprender cuál es la concepción del(de la) Educador(a) Social sobre la infancia a partir de sus trabajos en eses espacios también educativos. El procedimiento metodológico utilizado para colecta de datos fue la entrevista por medio de un cuestionario semi-estructurado. Las discusiones teóricas para análisis de los datos y fundamentación fueron pautadas en autores que desarrollaron conceptos sobre infancias y niñez. También fueron utilizadas publicaciones que relacionan las perspectivas de la Educación Social - Pedagogía Social con las concepciones de infancia. Problematizar la existencia de la infancia sob la perspectiva de la Educación Social - Pedagogía Social es comprender que esa infancia es determinada por un contexto social y cultural que irá delinear la existencia de aquel sujeto entendido como ser humano que es llamado niño. Otro abordaje para reflexión y que inspira esas discusiones es comprender que así como la escuela es oficialmente reconocida como espacio educativo que trabaja, entre otros grupos, con niños, y existe la defensa de la necesidad del preparo cualificado del profesional - profesor - que actúa en ese espacio, también existe la defesa de que el (la) educador(a) social también responsable por un proceso educativo específico, necesita de formación adecuada y condiciones para efectivar un trabajo educativo con calidad en su espacio de actuación profesional. A final la infancia presente en la escuela o en la institución de acogimiento y en los demás espacios educativos debe ser entendida como una fase de extrema importancia para el desarrollo humano, debiendo ser garantizado sus derechos de existencia plena de tranquilidad, ludicidad, amorosidad, cuidados, conocimientos, y demás factores que influyen su desarrollo cognitivo y afectivo.

Palabras claves: Infancia. Educación Social. Pedagogía Social.

\section{Introdução}

Esta pesquisa tem por temática as infâncias nas instituições de acolhimento em Ponta Grossa sob o olhar dos (das) educadores (as) sociais. O tema dentro das instituições e para a sociedade de modo geral é vista pelas pesquisadoras como de extrema importância e essencial para promover a garantia de toda criança ao direito à infância.

A infância, entendida como uma das fases mais importantes do desenvolvimento das capacidades humanas, precisa de destaque ainda maior quando voltada para a Educação Social, em que ocorrem grandes diferenças sociais, com certa parcela das crianças expostas a violência, ao abandono, violação de direitos e principalmente a miséria.

Assim por meio de pesquisa bibliográfica, apresentamos teorias que tratam da relação da Educação Social com a infância e o caminho da Educação Social/Pedagogia Social para a compreensão a mesma. Pautamo-nos em Johann Heinrich Pestalozzi, pois este é considerado um dos precursores da Pedagogia Social, dado que realizou registros de acolhimento de crianças em situações vulneráveis; como também, a cerca dos conceitos de Educação Social - Pedagogia Social e os âmbitos de intervenção do Educador (a) Social.

\section{O Educador Social Pestalozzi: o pai dos pobres}

Um dos precursores da Pedagogia Social, o qual pode ser definido como Educador Social, que possibilitou os primeiros registros de acolhimento se tratando de crianças em áreas de risco foi Johann Heinrich Pestalozzi, que traz em sua vida e obra uma 
perspectiva educativa fincada no social. Nascido em Zurich, em 1746, preocupava-se com a educação das classes populares, tendo em vista sua trajetória de vida, perdeu seu pai quando pequeno, deixando, além dele, a esposa e mais dois filhos em uma situação não muito favorável.

Desde muito cedo, Johann Heinrich mostrava-se disposto a ajudar as pessoas e se revoltava com situações de qualquer injustiça. Considerado o pai dos pobres, ele ressalta a importância da assistência ao menor desamparado e pobre. Sendo assim, inicia seu trabalho oferecendo alimento e uma sala aquecida em sua casa, num inverno rigoroso em 1774 na Suíça. Passado alguns anos, após ter construído um instituto de abrigados, teve que pausar este trabalho devido a problemas pessoais com sua esposa e filho.

Percebemos assim que as mazelas da sociedade sempre existiram e que com isso muitos ficam às margens, em situações de risco. Para além dos problemas sociais, o grupo de pessoas pertencentes à infância nem sempre foi muito considerado. Foram deixados de lado, pequenos sem possuidores de direitos. Junto a este grupo, os que não se enquadram numa família nuclear sempre foram alvo de olhares aos avessos.

Com o fim da Revolução Francesa, Pestalozzi oferece para ajudar 400 órfãos da guerra civil em Zürich. No ano de 1799, inaugurou o Orfanato de Stanz, num antigo convento, e logo, 80 desamparados eram atendidos.

Criticado por sua falta de método, Pestalozzi se justificava relatado por Würth (1971, p. 65):

Êle queria acordar primeiro as próprias energias íntimas destes meninos deixados por tanto tempo sem cultivo da sua personalidade, das suas capacidades, da sua fôrça íntima. Êle queria que ressurgisse em cada um, a confiança risonha que dá a coragem de agir. Êle queria reconduzir todos a um ponto no qual não haveria mais rancores, recalques, complexos de inferioridade.

Com isso, percebe-se que o renomado pedagogista se deteve em considerar cada criança como um caso específico, não tratando como se estes não obtivessem métodos, mas ressaltando suas particularidades e sobre elas desenvolveu didáticas para se trabalhar. Tendo tantas crianças em suas mãos, bem como cada uma carregada de sua história, não haveria um único método que daria conta de ressurgir no ímpeto, obtendo-se de resultados com certa rapidez.

Durante toda sua trajetória, o pai dos pobres precisou vencer diversos obstáculos, tendo por vezes que fechar um instituto de acolhimento e seguir para outros espaços iniciando seu projeto de vida e trabalho novamente.

Em 1804 mudou-se para um convento em Münchenbuchsee; aqui se inicia uma nova realização máxima para Pestalozzi em um antigo castelo. Por vinte anos desenvolveu seu trabalho, no qual ficou muito conhecido. Recebia muitas visitas com interesses em estudar seu método. Aqui novas ideias de instituição se configuram, houve a necessidade de se atender os filhos de famílias ricas, que pelo seu sucesso, enviavam seus filhos até Pestalozzi. Além destes, meninas começaram a ingressar no internato.

Curso de estagiários de magistério também foi algo novo para o pai dos pobres, logo se espalhando em outros municípios, propagando seus ideais. Contudo, Pestalozzi se via distante de seu objetivo e logo fundou perto de Yverdon um asilo para os menores pobres. Neste mesmo período acontece o grande auge da sua obra. Filósofos, pedagogos, intelectuais, escritores, todos estes desejavam o conhecer; e assim foi feito. Pestalozzi os recebe 
com intuito de pesquisas pelos seus métodos e escritos já então bem renomados na época.

Neste mesmo período o pedagogista apresentou algumas inovações pedagógicas consideradas revolucionárias. Desenvolveu atividades manuais, em hortas, oficinas, estudos, características essas que atualmente encontramos em instituições de acolhimento. Bem como, atividades físicas, jogos, festas de civismos, instrução pré-militar e momentos de oração, incluindo confissões, sempre conduzidas por Pestalozzi. A disciplina era uma de suas marcas, afinal, se fazia necessário inserir algumas regras aqueles que no instituto chegavam, e manter a ordem com os que dela já faziam parte.

Somente no final de sua vida é que consegue realizar um balanço das situações mais negativas de sua vida, reconhecendo seus enganos por ser um grande idealista. Continua ainda por publicar algumas de suas obras literárias, mas sendo por alguns, mal interpretado.

Em fevereiro de 1827, morre o então conhecido pai dos pobres. Pestalozzi deixara seu legado para além da ciência, do método ou da teoria. O pedagogo descreve o afeto como papel fundante para o trabalho com os acolhidos, ressaltando assim a importância do amor materno para as relações com aqueles que ele recebia. Idealizou assim, a sua escola como uma extensão do lar, inspirado no ambiente familiar, transmitindo aos pequenos segurança e afeto.

\section{Origens e conceitos da Educação Social - Pedagogia Social}

Ao se tentar descrever as origens, e principalmente os conceitos da Educação Social, percebemos que muitas descrições são encontradas, por assim, destacamos que "A Educação Social é uma prática pedagógica da Pedagogia
Social que se transforma num instrumento de promoção, libertação pessoal e comunitária, contribuindo para a construção de um mundo mais justo”. (PAIVA, 2015, p. 65).

A Pedagogia Social proporciona a reflexão daqueles que estão envolvidos com a Educação Social, os chamados Educadores Sociais que precisam estar preparados para enfrentar diferentes tipos de condições de vida dos educandos acolhidos, tendo em vista a reinserção familiar e social deste. Porém, apesar de exercer papel fundamental na sociedade, precisando lutar contra o sistema em sua atuação para proporcionar a transformação social também tem a desvalorização legal quanto a sua profissão, já que sua profissão não é regida legalmente.

O termo Pedagogia Social é de origem alemã, utilizado pela primeira vez em 1844, e pretendia inicialmente ajudar à juventude tanto educativa, quanto profissional e culturalmente. (PAIVA, 2015, p. 68).

Como colocado pela autora, a origem do termo é antiga, no entanto ainda se conhece pouco sobre o mesmo, apesar dos estudos ganharem espaço a partir dos problemas que a sociedade necessita enfrentar.

Segundo Ribas Machado (2010, p.74-75):

A Alemanha é considerada o berço da Educação Social e da Pedagogia Social, tanto no sentido de elaboração das terminologias e sua fundamentação, como também na organização e reconhecimento social. Cabanas (1997, p. 77) descreve que os pesquisadores alemães vinculam a aparição da Pedagogia Social, enquanto prática, ao surgimento da sociedade industrial, no sentido de que esse processo de industrialização da sociedade provocou um acúmulo de problemas que atingiu grupos humanos. As imigrações, greves, aglomerações urbanas, bairros periféricos, são considerados 
problemas que desestruturam a vida humana e que a educação social atua a partir desses problemas. $\mathrm{O}$ autor complementa que ela pode ser considerada um fenômeno recente, ela surge a partir dos problemas já relatados.

Percebemos com isso que o surgimento da Educação Social e Pedagogia Social esteve atrelado aos problemas sociais, fato este que perdura até os dias atuais, nos quais precisa ganhar cada vez mais espaço para que alcancemos o objetivo de uma sociedade mais justa e humana.

Neste sentido é que se destaca Herman Nohl citado por Ribas Machado (2010, p. 76):

É nesse contexto que tem destaque o pedagogo Herman Nohl (1879 - 1960), considerado o pai da Pedagogia Social na Alemanha. Sendo professor de pedagogia em Jena, seus discípulos incentivaram-no a dar lições referentes à Pedagogia Social, que era confundida com a educação popular, no sentido de uma educação voltada para a população em geral. Foi assim que Nohl fundou a Universidade Popular em Jena, sendo que a época conturbada do pós-guerra o colocou em contato com os verdadeiros temas da Pedagogia Social. Proferiu um seminário onde discutiu os problemas que afetavam a muitos jovens e orientou a atenção social necessária aos mesmos por meio de um trabalho interdisciplinar com enfoques educativos, estabelecendo interlocuções com a área jurídica, a psiquiatria e o trabalho social. Essa foi a estruturação inicial da Pedagogia Social, sendo Nohl o responsável por sua organização, sendo que também tentou buscar meios para considerá-la uma área profissional, mas acabou por elaborar apenas a fundamentação teórica da área da Pedagogia Social, produzindo um grande número de escritos sobre o tema.

Considerado o pai da Pedagogia Social por ser o responsável por impulsionar a
Pedagogia Social como uma disciplina específica, Herman Nohl, foi de grande importância para as discussões acerca dos problemas sociais, tendo como base o enfoque no pedagógico e no social, para assim obter melhores resultados.

No Brasil, a Pedagogia Social ainda precisa de mais pesquisas se comparada a outros países, porém é impossível desprezá-la diante dos diversos contextos de desigualdades sociais a que nos deparamos atualmente. Apenas a Pedagogia Escolar não é suficiente para acolher todas as crianças que cada vez mais adentram tanto as escolas quanto os espaços de Educação Não Formal com tantos caminhos de vida diferentes. É preciso uma área que entenda essas crianças como sujeitos, que promovam a esperança de se viver em um mundo mais justo, torná-los sujeitos reflexivos e críticos e de conhecimento de seus direitos. Essa área se nomeia como Pedagogia Social a qual vê todos de forma igualitária e pertencentes dos mesmos direitos.

Fichtner (2010) citado por Paiva (2015, p.70) afirma que:
A Pedagogia Social procura responder per- guntas a respeito do processo de integração do indivíduo a sociedade, tanto do ponto de vista teórico como prático. Trata dos pro- cessos do crescimento humano que amar- ram as pessoas aos sistemas, às instituições e às comunidades, que são importantes para o seu bem-estar e para a gestão de suas vidas. A ideia básica da Pedagogia Social é promover o funcionamento social da pes- soa: a inclusão, a participação, a identidade e a competência social como membros da sociedade.

O/A educador (a) que trabalha com as mais variadas condições de vida em uma extensa lista de espaços é chamado de Educador Social e por atuar em certa diversidade de ambientes, além também do motivo ponderal 
de que trabalham com diferentes tipos de sujeitos, o Educador Social precisa estar sempre em busca de novos conhecimentos, refletindo ações que possam permitir a transformação ou melhoria das condições de vida de tais sujeitos.

A Pedagogia Social assim vem ao encontro com as mazelas da sociedade para superação da sua própria história. Consideramos a importância do ganhar espaço da Pedagogia Social, pois é ela quem contribui com a Pedagogia Escolar, como também, se aprofunda nas questões sociais e familiares dos educandos.

\section{Âmbitos de intervenção da Educação Social - Pedagogia Social}

Com a história da humanidade, bem como os movimentos de lutas, notamos que as demandas sociais exigem que o educador possa atingir vários âmbitos no que diz respeito à educação. Portanto, para além da Pedagogia Educacional, temos a Pedagogia Social, um desmembramento da primeira que estuda e tem por objetivo a educação em diferentes espaços.

Compreendendo assim, os denominados educadores sociais desenvolvem seus trabalhos em diversas áreas, nas quais possuem finalidades próprias direcionadas aos envolvidos. Salientamos que as concepções e ações tomadas frente aos envolvidos irão deixar claro qual é a finalidade fundante do processo de formação, que pode estar relacionada com a manutenção da situação ou com o avanço e o reinserir do sujeito na sociedade. Com relação a esse relato Ribas Machado (2010, p. 44) complementa:

As diferentes práticas de Educação Social podem ser encontradas em vários espaços: diferentes ONGs (com diversos enfoques, várias origens de financiamentos, diferentes interesses); Instituições Abrigos (espaços em que as pessoas frequentam por determinados períodos e ou definitivos); Presídios (existem muitos estudos sobre a educação em presídios, que é muito peculiar); Hospitais (existem estudos avançados na área da Pedagogia Hospitalar); Educação de Jovens e Adultos (vários projetos e programas existentes de diferentes maneiras para efetivar essa meta); Movimentos Sociais (muitas práticas são educativas em Movimentos, a própria participação já configura um tipo de formação); Igrejas (práticas educativas com intenções específicas); Projetos Sociais; Programas Sociais (existe uma gama de ações, denominadas de sociais, que atuam em perspectiva educativa, em meios como a rua, além de outros); Escolas (na própria escola são reconhecidos espaços de práticas de Educação Social, como por exemplo, projetos de contra-turno, etc.). Esses são apenas alguns dos espaços, contudo, essa lista pode ser mais extensa. Essa diversidade de práticas educativas exige pessoas que se tornem responsáveis por elas.

A citação acima revela o vasto campo acerca da Pedagogia Social e, com isso, salientamos a figura do Educador (a) Social neste processo. Infelizmente, não temos um curso de graduação que seja voltado para a Pedagogia Social, deixando a desejar que os acadêmicos possam assim conhecer os demais campos de atuação para além da escola.

A partir disso, é importante salientar que o profissional que atua nestes outros campos são pessoas que possuem entre nível médio e graduação em Licenciatura em Pedagogia. Isto não quer dizer que não seja o bastante, mas defendemos a ideia de um curso específico na área e que este seja o principal requisito para os desbravadores de outros espaços educacionais. Salientamos que com isso, pouco se sabe acerca dos chamados 
Educadores (as) Sociais. Para além de cursos específicos na área, percebe-se a necessidade de uma secretaria nos municípios que, diretamente tomem conta de todas as áreas que competem a Pedagogia Social para assim, legitimar este campo.

O/a Educador/Educadora Social precisa ter como princípio a transformação da realidade dos que dele o cercam, faz-se necessário o aproximar da criança ou adolescente que fora colocado em situação de risco por negligências dos adultos que deveriam os amparar. Esta não é uma função fácil e limitada a ser realizada, é preciso que ocorra um trabalho efetivo com os Educadores/Educadoras Sociais para que consigam desempenhar suas funções de modo que contribua, some a vida dos que estão em condições vulneráveis.

As crianças alojadas em instituições de acolhimento, na maioria das vezes já por sua condição de vida familiar ficam distantes de vivenciar a infância, já que essas são afastadas do meio de convívio familiar por motivos significativos como negligência da família biológica dentre tantos outros motivos. O escape para essas crianças que já tiveram parte de sua infância recolhida pode estar inclusa nas instituições de acolhimento que precisam estar preparadas para garantir o direito da infância para a mesma.

Historicamente sabemos que crianças são abandonadas por miséria, pobreza, dúvida de paternidade, sexo da criança indesejável. No século XVI as crianças nascidas fora do casamento eram afastadas da família para que a moralidade fosse preservada. Nessa época a Igreja, ligada ao Estado, criou meios para a proteção dessas crianças que eram de certa forma excluídas do meio familiar e da sociedade, criando espaços de acolhimento nas quais o Estado era responsável pela construção e manutenção dessas instituições além do pagamento das amas-de-leite que eram responsáveis pela alimentação e pelo cuidado das crianças institucionalizadas. Porém, pelo baixo pagamento, pelo grande número de crianças fazendo com que muitas fossem cuidadas por uma única ama-de-leite fez com que os índices de mortalidade fossem elevados, principalmente pela falta de higiene durante a alimentação e da própria estadia da criança com as responsáveis.

Na Idade Média surge a preocupação com as crianças abandonadas, de que essas sofressem algum tipo de maltrato antes de chegar à instituição já que algumas eram deixadas nas ruas, assim surge a roda dos expostos em meados do século XVII. Essa forma de acolhimento das crianças era um meio de manter as desigualdades e garantir a ordem da sociedade pela obediência, além de ser visto como um "mal" necessário para os acolhedores fazerem o bem e, assim, garantirem o reino dos céus.

Atualmente, temos as instituições de acolhimento que recebem crianças e adolescentes com intuito de reinserção familiar, assim questionamo-nos sobre a relevância da infância dentro destes espaços na qual os pequenos passam a conviver. Para que as tentativas de reinserção com a família de origem não se esgotem ou para que outras possibilidades surjam para que a criança não passe mais que dois anos no acolhimento é necessário que todos os envolvidos estejam preparados, conforme cita Oliveira (2007, p. 22):

O abrigo, apesar de oferecer condições de vida semelhantes às de um ambiente residencial, supere o atendimento caseiro. É preciso contar com serviços de profissionais habilitados e capacitados para promover a proteção integral que essas crianças e adolescentes necessitam. E a proteção integral vai muito além da oferta de habitação, alimentação, educação, atendimento médico, vestuário e lazer entre outros. 
Nesse sentido sentimos a importância da infância como âmbito de intervenção da Educação Social, na qual cabem práticas para proporcionar a essas crianças institucionalizadas condições de vida mais dignas, promovendo a sua proteção integral garantindo seus direitos e inserindo-as a sua família de origem e à sociedade.

Percebemos que Pestalozzi se preocupava com as condições básicas das crianças que acolhia, bem como as colocava em algumas regras para que pudesse desenvolver seu trabalho tão almejado, o de acolher os pequenos mais necessitados. Assim, como desde em sua época, notamos que o (a) Educador (a) Social pode e deve priorizar a etapa da infância dentro da instituição em que os pequenos acabam por ser enviados.

\section{Sentidos sobre infância - Que crianças são essas? Que infância é essa?}

O conceito de infância nem sempre foi da maneira que temos hoje, houve vários contextos e períodos históricos que delinearam o caminho para chegarmos à definição que hoje temos. Em tempos remotos não se tinha qualquer valorização da infância, as crianças eram vistas como adultos em miniaturas, onde faziam a mesma coisa que os mesmos, se vestiam como tais e não tinham o seu direito a infância garantida.

Atualmente, podemos dizer que a partir da Constituição Federal e do Estatuto da Criança e do Adolescente o direito a infância fora a eles garantido, no entanto em termos de lei, pois dizer que a criança tem seu direito à infância não é sinônimo de dizer que ela é possuidora da mesma. Assim vemos múltiplas infâncias, que vão surgindo em cada período e em cada contexto, desde aquelas nas quais as crianças de fato têm esse direito preservado e assegurado até aquelas que por fatores diversos são privadas de vivenciar a infância em sua plenitude.

A infância, considerada uma fase de extrema importância na vida dos seres humanos, da base de sua história e de inúmeras descobertas soma-se a necessidade de proteção daqueles que cercam a criança desde seus primeiros dias de vida, ou até mesmo, porque não, desde a descoberta da gestação.

De acordo com Belloni (2009, p. 1):

Falar de infância significa, do ponto de vista sociológico (ou macrossocial), utilizar a categoria geração para compreender os fenômenos sociais; categoria que, tal como classe, gênero, ou escolaridade, pode ser entendida como variável explicativa, de uma forma ou de outra, mais ou menos determinante. Essa é a primeira precisão fundamental para a compreensão do fenômeno em questão e significa que podemos compreender e explicar fatos, comportamentos, ações e estruturas sociais com base nessa categoria - infância- construída teoricamente a partir da "escuta" dos fatos sociais. Também implica estabelecer relações entre a categoria geração e as estruturas sociais no sentido de compreender quais as determinações sociais do processo de socialização das novas gerações, qual o grau de autonomia que estes grupos sociais (crianças e adolescentes) têm, nas sociedades contemporâneas tecnificadas e globalizadas, bem como quais diversidade sociais e regionais são mais pertinentes. Desafios de grande porte proporcionais à complexidade do fenômeno.

Notamos assim que a autora descreve que, para elucidar aspectos sobre infância, é preciso considerar a categoria e os fenômenos sociais, para assim desenvolver o foco primeiro, a infância. Infância aqui compreendida para além de uma etapa biológica dos seres 
humanos, mas algo constituído historicamente que veio ganhando espaço e novos desafios.

Philippe Ariès, em sua obra intitulada História Social da Criança e da Família, traz um recorte acerca da infância, relata as transformações dos sentimentos em relação à criança desde a Antiguidade até a sociedade Moderna. Obviamente não podemos tratá-la como única, uma vez que devemos sobrelevar que o autor fez um recorte da infância, sendo necessário destacar que existem outras infâncias em outros lugares e tempos históricos, mas que este fora reconhecido como um pioneiro no que tange a discussão.

Ariès descreve que os pequenos por muito tempo não eram reconhecidos, bem como sua perda também não era notada caso uma criança viesse a morrer, pois logo outra viria em seu lugar. Em suas palavras Ariès (2014, p. X) ressalta:

Contudo, um sentimento superficial da criança - a que chamei de "paparicação" - era reservado à criancinha em seus primeiros anos de vida, enquanto ela ainda era uma coisinha engraçadinha. As pessoas se divertiam com a criança pequena como com um animalzinho, um macaquinho impudico. Se ela morresse então como muitas vezes acontecia, alguns podiam ficar desolados, mas a regra geral não era fazer muito caso, pois uma outra criança logo a substituiria. A criança não chegava a sair de uma espécie de anonimato.

Anonimato esse relatado pelo autor que infelizmente ainda encontramos, pois para alguns, senão muitos, as crianças são meros seres receptivos de tudo aquilo que os adultos podem lhe contribuir como se fossem gavetas armazenadoras do aprender. $\mathrm{O}$ autor ainda destaca que logo ao se aprender a andar, os pequenos já eram introduzidos aos afazeres junto a seus responsáveis, sendo a estes ensinados os ofícios que por suas famílias eram desenvolvidos.

Notamos esta prática também em nossos dias atuais. Muitas crianças, por necessidades da família, desde muito cedo já desenvolvem alguma atividade para ajudar em casa em seu próprio sustento, outras por vezes são exploradas. Com o passar do tempo, como descreve Ariés à criança tem uma participação maior no seio familiar, juntamente como o processo de escolarização dos pequenos, já que estes deixam de aprender somente os ofícios exercidos pelos seus responsáveis.

Ao se desejar descrever os sentidos da infância, tomamos como direção o questionamento de que toda criança é possuidora de infância? Uma vez que percebemos as desigualdades a luz do dia; desigualdades estas que nos colocam a pensar, a refletir na sociedade que vivemos, na sociedade que promovemos as crianças, bem como o acesso, a emancipação, os seus direitos.

Valemo-nos aqui de Paula (2015, p. 44):

Privação, exploração, escravidão e preconceito foram algumas das marcas deixadas nas crianças e adolescentes no início da sociedade brasileira, sendo problemas que avançaram ao longo dos séculos martirizando nossas crianças e adolescentes. Quem são aqueles que deixaram sua cultura nativa na época do Brasil Colônia para viver uma pseudoinfância envolto a crueldade exploratória daqueles que ditavam as regras da sociedade que ora iniciava. Não deixando de existir, mas, atualmente moldado pelo "avanço da humanidade", problemas no contexto atual da sociedade brasileira, são crianças vivendo em meio à miséria, pobreza material e excluídas dos direitos necessários para um crescimento sadio, são estes, os privados dos subsídios estruturais, que vivem e geram problemas em sua adolescência, de fato, a marginalização do ser humano pode ser mapeada 
pela observação da estrutura familiar e social.

Infelizmente este grupo social, dos pequenos, de certa forma, foram colocados a reserva, deixados de lado, sem que houvesse preocupação com estes, os excluídos de seus direitos. Entre 1922 e 1923 no Brasil houve um crescimento de instituições privadas, vinculada a Igreja Católica, na qual se atendia órfãos e crianças retiradas das ruas com objetivo de prepará-los para o trabalho e doutriná-los sobre moral. As edificações aqui, destas instituições, eram muito parecidas com quartéis, na qual se prezava a disciplina e o isolamento dos pequenos ali inseridos.

De acordo com Poletto (2012, p. 4): "No ano de 1927 instituiu-se o Código de Menores, no qual se destaca a nítida criminalização da infância pobre, caracterizada como 'abandonada' e 'delinquente'.". Aqui surge também o termo menor a estes acima caracterizados, onde o autor ainda complementa:

Esse Código trouxe o início do atendimento às crianças e aos adolescentes através de uma política específica, onde utilizava para os adolescentes infratores o internato, o perdão cumulado com advertência (semelhante à atual remissão) e a liberdade vigiada. (POLETTO, 2012, p. 5).

Os menores assim eram conduzidos aos internatos com intuito de uma reeducação militarizada, na qual todos deveriam se enquadrar as regras.

Observemos que estes já eram privados de seus direitos, eram culpados pela sua vida, por sua conduta, esquecendo, deixando de lado, toda circunstância que a sociedade lhe impunha. Muitas das instituições desenvolvem seus trabalhos mediante a disciplina, regras, deveres, o que para alguns, não deve ser muito fácil, acabando por vezes em se rebelar contra aqueles que deles tomam conta, afinal temos que compreender todo o processo que se passa por estes que chegam até as instituições.

Sabemos que se faz necessário que as crianças cresçam com disciplina, afinal, elas precisam disso para sua vida futura, porém, não se deve priorizar isso, deixando de lado a etapa primordial de sua vida. A infância deve ser respeitada e contemplada em todos os espaços que ela assim ocupa.

A partir disso, notamos que a infância foi sendo constituída historicamente, e que, ao lado dos atendimentos a ela direcionados, também foi se ampliando ao que tange no conceito e nas especificações do sujeito criança. Para Quinteiro (2001, p. 149):

Neste sentido, a história da infância coincide com a história da assistência, do atendimento às crianças em situação de risco, no que também contribui para a produção da imagem da criança pobre que é sempre vistas como uma ameaça social a ser contida.

Ameaça social que para muitos ainda é visto, pois as representações das crianças que muitos hoje consideram, são aquelas que possuem um núcleo familiar, que frequenta escola, que possui acesso às demais boas condições. A precariedade da vida, a desigualdade é tirada de cena, e não muito incomum, notamos a sociedade fechando os olhos para aqueles que com um pequeno gesto, pedem ajuda, socorro, pedem condições igualitárias, ou pelo menos, melhores de vida.

É forte a questão de que tange o contexto social como ponto referencial para as múltiplas infâncias, é preciso considerar seus avanços, mas principalmente os retrocessos para que se possa chegar ao ponto do que ainda precisa vir a ser melhorado e para isso é necessário partir do social e mais específico ainda no contexto capitalista em que vivemos, onde temos demarcadas duas classes sociais, 
a classe dominante e a dominada para pensar em políticas que viabilizem a reinserção da sociedade popular de forma democrática e humanitária.

\section{Representações de infância por parte dos (das) Educadores (as) Sociais nas instituições de acolhimento de Ponta Grossa}

Para chegarmos a nosso objeto de pesquisa e pudéssemos problematizar a concepção de infância dos (das) educadores (as) sociais, trabalhamos com algumas instituições cadastradas no Conselho Municipal dos Direitos das Crianças e dos Adolescentes (CMDCA) do município de Ponta Grossa, das quais se somam cinco instituições voltadas ao trabalho com crianças. Essas concepções foram levantas a partir de um questionário semiaberto aplicado durante o primeiro semestre de 2016.

A metodologia utilizada para essa pesquisa é de cunho exploratório, a qual permite maior familiaridade do pesquisador com o tema, partindo de hipóteses e intuições. Se tratando de um assunto pouco conhecido como citado por Gil (1999, p. 43) "Este tipo de pesquisa é realizado especialmente quando o tema escolhido é pouco explorado e torna-se difícil sobre ele formular hipóteses precisas e operacionalizáveis.", mas é um assunto que vem ganhando cada vez mais espaço em pesquisas e interesse de pesquisadores pela necessidade emergente de buscar soluções para diminuir a vulnerabilidade da classe economicamente desfavorecida. Este tipo de pesquisa vem ao encontro com a finalidade dessa, partindo de levantamentos bibliográficos, citações e exemplos que tornam o entendimento do leitor mais prático e promovendo a sua reflexão sobre, além da utilização de questionário para coleta de dados.
O caminho que segue essa pesquisa não é linear, considerando diversos fatos que surgem durante a pesquisa não focando apenas no resultado, mas sim no processo que se deu a pesquisa como um todo, considerando desde a aceitabilidade das instituições participarem até se chegar na concepção que os educadores (as) sociais tem sobre a infância.

O critério para o número de questionários que seriam deixados nas instituições foi através de conversa com um responsável, nesse caso, com Assistentes Sociais, Psicólogos ou Educadores (as) Sociais da instituição, que forneciam a informação de quantos Educadores (as) Sociais se faziam presentes e que poderiam vir a participar da pesquisa. Foram distribuídos vinte e dois questionários ao todo, e obtivemos como retorno dez questionários das instituições participantes. Somando as questões dos questionários, oito das treze questões são abertas, onde os participantes puderam expressar sua ideia sem qualquer interferência.

Dentre as instituições, tivemos em média de retorno dois a três questionários, totalizando dez participantes, sendo três do gênero masculino e sete do gênero feminino, sendo assim a maioria. Como em Ponta Grossa não há formação específica na área de Educação/ Pedagogia Social, os participantes possuem formação em Serviço Social, Psicologia, Filosofia, Educação Física, Marketing, Pedagogia, Processos Gerenciais, afinal o critério a ser utilizado para o desempenho de suas funções é apenas o Ensino Médio.

Ao serem questionados a cerca do tempo de trabalho em cada instituição, oito dos participantes trabalham a menos de um ano no espaço, em tempo integral, justificando o fator salarial e devido ao trabalho que se exige desse Educador (a) Social, o qual não pode ser fragmentado já que as crianças moram na 
instituição. Todas essas questões fora colocadas de modo fechado aos participantes.

As cinco últimas questões correspondem às particularidades de cada participante e de instituição. Assim sendo, a primeira pergunta refere-se ao que fez despertar o interesse do educador (a) em trabalhar na instituição de acolhimento, as respostas foram referenciadas a questão do proporcionar cuidado, ajudar as crianças de alguma maneira, pelo amor as crianças e por julgar ter perfil profissional para lidar com crianças em situações de vulnerabilidade.

A próxima questão se refere ao entrevistado, se o mesmo como Educador (a) Social considera importante saber sobre a vida da criança e o porquê. As respostas aqui foram pautadas na questão do cuidar e acolher a criança para melhor direcionar seu trabalho, o que contribui nas maneiras de intervir, sendo cauteloso nos momentos de falar, ouvir e advertir quando necessário.

A questão seguinte diz acerca do que é necessário para se trabalhar com uma criança acolhida. As respostas aqui se repetem bem no que tange aos cuidados primários, como de um processo de adaptação e ressocialização da criança institucionalizada.

A quarta questão por nós colocada, é direcionada ao que os Educadores (as) Sociais concebem o que é infância, nesta questão as respostas se aproximam, uma vez que os participantes descrevem como uma etapa importante da vida; todos responderam com base na infância que tiveram, com a infância por todos nós idealizada para todas as crianças.

A quinta questão pelos entrevistados respondida fora acerca de como é realizado o trabalho com a infância em cada instituição, na maioria das respostas os participantes destacam a importância do manter a essência da infância aos acolhidos, resgatando o brincar, a importância do ensino, tarefa, dando-lhes carinho, atenção, e também destaca-se como um trabalho desafiador e complexo devido ao contexto em que as crianças e adolescentes chegam até as instituições.

A próxima problemática que fora aos Educadores (as) Sociais realizada refere-se ao que uma criança acolhida precisa. A maioria das respostas circundam entre amor, cuidado, ensino, respeito, carinho, atenção, sabemos bem que estas necessidades cabem a todas as crianças, independente da situação de vida, porém, esse foco no assistencialismo, nos sentimentos não irá dar base para tudo o que as crianças precisam, estas necessitam de atendimento individualizado, é importante cuidar sim, mas ir além das necessidades primárias que a cercam e ofertar a vida e os seus direitos.

Como última questão de nosso questionário, mas não menos importante, tivemos o intuito de descobrir quais eram as facilidades e dificuldades encontradas ao se trabalhar numa instituição de acolhimento. Aqui tivemos respostas diretas e sem muita exploração, como também pudemos conhecer um pouco mais sobre as fragilidades encontradas pelos Educadores (as) Sociais durante a sua jornada de trabalho. Muitos descrevem a cerca da falta de formação, conhecimento para o desenvolvimento do trabalho, como também a dificuldade quando chegam até as instituições adolescentes com grande comprometimento, desvalorização do profissional; como facilidades a maioria descreve sobre os espaços e equipamentos que possuem, o número de colaboradores e a diversidade de atividades existentes.

Com base em nossa pesquisa, notamos que inúmeras são as concepções de infância e de criança, o que é um ponto positivo, afinal, destacamos que ambos os conceitos são visivelmente plurais e que não são consequentemente, sinônimos. Ainda há de se elucidar 
que, as ações pelos Educadores (as) Sociais desenvolvidas, são múltiplas, nas quais muitas vezes são realizadas sem uma direção específica por não haver isso em comum para todas as instituições.

Como cada instituição desenvolve seu trabalho, pautado em particularidades, como por exemplo, com base religiosa, cada uma tem uma maneira própria de se organizar, mas durante os contatos estabelecidos entre as pesquisadoras e as instituições, todas alegaram que se pautam em um documento do Ministério do Desenvolvimento Social e Combate a Fome - Secretaria Nacional de Assistência Social, chamado Orientações técnicas sobre o Serviço de Convivência e Fortalecimento de Vínculos para crianças e adolescentes de 6 a 15 anos - Prioridade para crianças e adolescentes integrantes do programa de erradicação do trabalho infantil, que discute sobre a proteção às crianças e adolescentes em situação de vulnerabilidades, casos de trabalho infantil, como ocorre o Serviço de Convivência e Fortalecimento de Vínculos como também de sua própria organização.

Este documento trata de situações e de como desenvolver o trabalho com as crianças que chegam até as instituições, pautadas em leis que os garantem o acesso e a permanência neste espaço, porém como já colocado, cada instituição possui particularidades devido sua história e base religiosa, quando pertencente a uma.

\section{Considerações finais ou conclusão}

Esta pesquisa teve como objetivo conhecer como a infância vem sendo vista e trabalhada nas instituições de acolhimento que atendem crianças no município de Ponta Grossa-PR, porém voltada para o olhar do Educador (a) Social, que é quem está mais próximo dessas crianças institucionalizadas.
Educador (a) Social aqui reconhecido como todo o profissional que trabalha diretamente com as crianças, como os Assistentes Sociais, Psicólogos, Mães Sociais, que moram com as crianças institucionalizadas, Religiosos, entre outros.

Para tal pesquisa buscaram-se as origens da Pedagogia Social/Educação Social e suas relações com a infância. Visto que essa fase é de extrema importância para o desenvolvimento de qualquer criança, na qual faz grandes descobertas e se descobre pertencente ao mundo, para crianças institucionalizadas vindas de grandes diferenças sociais e expostas a tantos sofrimentos isso se faz ainda mais relevante. É, portanto, de extrema importância o trabalho do Educador (a) Social que irá atender e auxiliar essa criança, trabalhando de forma a respeitá-la, valorizá-la e fazendo a mesma se sentir e pertencer a um grupo social.

De acordo com os dados levantados, alguns dos Educadores (as) Sociais das instituições pesquisadas partilham do entendimento da importância da proteção da infância visto que em algumas respostas obtidas apresentou-se na escrita a tentativa em manter a infância dos acolhidos através de brincadeiras e outras intervenções, resgatando a infância dos mesmos que muitas vezes se fez perdida no seu ambiente familiar.

Ainda, acerca do (a) Educador (a) Social, percebemos que por influência da não formação específica da área, muitos ainda trabalham com as crianças de modo assistencialista, na qual as crianças necessitam de atenção, carinho, amor, autoestima, valores, saber ouvir, resgatar laços familiares para se sentirem pertencentes aquele espaço e de modo a minimizar as mazelas da vida. Os dados levantados nos foram reveladores, pois quando mostram as concepções das instituições de acolhimento que deveriam estar voltados ao desenvolvimento intelectual das crianças, 
visando sua reinserção na sociedade de modo que venham a compreender as situações e os contextos que as permeiam, ainda estão muito relacionadas ao cuidado, às necessidades primarias dos seres humanos. É perceptível que Johann Heinrich Pestalozzi, mesmo que inconscientemente para esses Educadores (as) Sociais, ainda seja um reflexo para as ações por eles realizadas; afinal ele descrevia o afeto como papel fundante para o trabalho com os acolhidos, para mais, ressaltava a relevância do amor materno nas relações com os pequenos, o que podemos até relacionar, com nossos dados. Tendo em vista, a pesquisa feita com os (as) Educadores Sociais, percebe-se que a maioria é do sexo feminino, talvez por favorecer essa relação com as crianças da instituição. Também deve se levar em conta que a maioria das vagas dos cursos de Pedagogia e licenciaturas são preenchidas por mulheres, o que gera uma demanda maior de mulheres para o trabalho de Educador Social. Isso é necessário ser rompido, a ideia de maternidade não deve ser requisito para o desenvolver do trabalho nas instituições, ainda parafraseando Pestalozzi, que considerava a escola como uma extensão da escola, num ambiente familiar, transmitindo segurança e afeto. É preciso ir muito além disso tudo, todos desejamos ser bem tratados, que alguém esteja disposto a nos cuidar, porém, a estas crianças muito já fora privado, muito do que estas já passaram não pode ser reparado. É de extrema importância que o cuidar e o educar sejam trabalhados de forma indissociável, tendo a cautela de não deixar o cuidar sobrepor-se ao educar, visando à formação integral das crianças e não apenas garantir a elas o suporte assistencial. Em nosso município não há um curso específico que forme profissionais na área da Educação Social. Essa falta de formação profissional específica afeta a qualidade do Educador em sua intervenção junto à criança. Com base na questão acima mencionada, é muito importante que se desenvolva um curso superior específico na área de Educação Social para suprir essa carência profissional que saiba intervir na realidade complexa das crianças que vivem nessas instituições, com base numa formação profissional de qualidade. Formação esta que considere o contexto das crianças já institucionalizadas em cada instituição, compreendendo sua trajetória enquanto espaço de acolhimento, como também, o compreender dos que já desenvolvem trabalhos nestes espaços. Segundo Ribas Machado (2010, p. 43-44):

[...] Desse ponto de vista, a concepção de
construção de conhecimento, a transforma-
ção da realidade e a emancipação através
da conscientização crítica dos fatos do co-
tidiano, bem como a Educação Social po-
dem ser considerados meios pelos quais as
práticas educativas alcançam tais objetivos.
Isso não significa dizer que a educação que
acontece na escola não possa ter a mesma
finalidade.

A Educação Social como prática educativa nos mais diversos ambientes, teoricamente, pode ser compreendida da forma como foi descrita acima. Entretanto, com a grande diversidade de meios onde acontecem práticas educativas, com os mais variados interesses, a Educação Social pode assumir uma perspectiva totalmente contrária a que teoricamente se defende. Em outras palavras, por meio de projetos, programas e instituições essas práticas educativas podem contribuir em um processo de apenas manutenção da realidade, colocando cada um no "seu lugar", por assim dizer. Seriam práticas assistencialistas, no sentido ruim do termo, seriam práticas que não possuem a perspectiva de transformação da realidade.

A existência destes espaços comprova como ainda nós, enquanto sujeitos, precisamos nos emancipar, quanto precisamos 
superar nossas diferenças e compreender que fazemos parte de um todo, de algo sensacional que se chama vida e que dela devemos experienciar o que há de melhor desde que nascemos. Nossa pesquisa assim teve por finalidade contribuir para as análises da Educação Social/Pedagogia Social, que ainda estão no início em nosso município, bem como coadjuvar no que tange aos trabalhos realizados nas instituições de acolhimento, afinal, nossas crianças estão em todos os espaços e não podemos isolá-las em uma instituição e esquecermos que estas fazem parte de nossa sociedade, bem como responsabilizá-las por estarem nestes locais. Precisamos deixar claro que estas foram vítimas de uma sociedade, de um grupo social, e são estas, que num primeiro momento necessitam de cuidados específicos, mas também, de um atendimento especializado e com garantia de uma reinserção familiar, social ou de adoção, num trabalho pautado na responsabilidade e no comprometimento com as crianças acolhidas.

\section{Referências}

ANDRADE, L. B. P. Tecendo os fios da infância. Disponível em: <http://books.scielo.org/id/h8pyf/pdf/ andrade-9788579830853-06.pdf >. Acesso em: 12 ago. 2016.

\section{ARIÈS, P. História social da criança e da} família. Rio de Janeiro: LTC, 2012.

ARROYO, M. G. A infância repõe o trabalho na agenda pedagógica. In: ARROYO, M. G.; VIELLA, M. A. L.; SILVA, M. R. (Orgs.). Trabalho-Infância: exercícios tensos de ser criança. Haverá espaço na agenda pedagógica? Petrópolis: Vozes, 2015.

BELLONI, M. L. O que é sociologia da infância. Campinas: Autores Associados, 2009.
BRASIL. Conselho Nacional de Educação. Diretrizes Curriculares Nacionais para o Curso de Pedagogia. Disponível em: $<$ http://portal.mec.gov.br/cne/arquivos/pdf/ pcp05_05.pdf> Acesso em: 12 ago. 2016.

BRASIL. Constituição (1988). Constituição da República Federativa do Brasil: promulgada em 5 de outubro de 1988. Disponível em: <http://www. planalto.gov.br/ccivil_03/constituicao/ constituicaocompilado.htm>. Acesso em: 07 ago. 2017.

Estatuto da criança e do adolescente: Lei federal $\mathrm{n}^{\circ}$ 8069, de 13 de julho de 1990. Brasília. 1990.

BERNARDI, D. C. F. (org.) Cada caso é um caso: estudos de caso, projetos de atendimento. São Paulo: Associação Fazendo História: NECA - Associação dos Pesquisadores de Núcleos de Estudos e Pesquisas sobre a Criança e o Adolescente, 2010.

BROERING, A. S. A "descoberta" da infância ocidental na modernidade: quais crianças foram "colocadas nesse berço"? Revista Linhas, Florianópolis, v. 16, n. 30, p. 270-285, jan.-abr. 2015.

CASTILLO, M. El educador social y la infância. Revista de Educación Social, Espanha, n. 4, setembro, 2005. Disponível em: < http://www.eduso.net/ res/?b=7\&c=64\&n=181>. Acesso em: 12 ago. 2017.

DELGADO, P. A criança em risco e a relação Escola - Família. Protecção e sucesso educativo. Revista interuniversitária de Pedagogía Social, Espanha, p.122-133, março, 2008.

DELGADO, P.; CARVALHO, J.; PINTO, V. S. Crescer em família: a permanência no acolhimento familiar. Revista 
interuniversitária de Pedagogía Social, Espanha. p. 123-150, 2014.

FERNÁNDEZ. A.; NIETO, N. La institución: "una balsa en medio del mar". Revista de Educación Social, Espanha, n. 4, setembro, 2005. Disponível em: < http:// www.eduso.net/res $/ ? \mathrm{~b}=7 \& \mathrm{c}=54 \& \mathrm{n}=163>$. Acesso em: 12 ago. 2017.

FONSECA, J. J. S. Metodologia da pesquisa científica. Fortaleza: UEC, 2002.

FREITAS, M. C. de. Para uma sociologia histórica da infância no Brasil. In:

História social da infância no Brasil. São Paulo: Cortez, 2016. p. 21-29.

FREITAS, M. C. de; KUHLMANN JR., M. Os intelectuais na história da infância. São Paulo: Cortez, 2002. p. 11-60.

GIL, A. C. Métodos e técnicas de pesquisa social. São Paulo: Atlas, 1999.

GRACIANI, M. S. S. A pedagogia social. São Paulo: Cortez, 2014.

GUEDES, C. F. Acolhimento institucional na assistência à infância: reflexões a partir da experiência de um abrigo. 2012.

HALMOS, C. Como ouvir as crianças: e responder às suas perguntas mais difíceis. Rio de Janeiro: Zahar, 2014.

JOLONCH, A. Educación e infancia en riesgo. Acción y reflexión en el ámbito social. Revista de Educación Social, Espanha, n. 4, setembro, 2005. Disponível em: <http:// www.eduso.net/res/?b=7\&c=54\&n=159>. Acesso em 12 ago. 2017.

KLEIN, L. R. Cadê a criança do Ariès que estava aqui? A fábrica comeu. In: IX SEMINÁRIO NACIONAL DE ESTUDOS E PESQUISAS "HISTÓRIA, SOCIEDADE E EDUCAÇÃO NO BRASIL”, 2012, João Pessoa. Anais... João Pessoa: Universidade Federal da Paraíba, 2012. p. 3374-3393.
KUHLMANN JR, Moysés. Infância e educação (1820-1950): comparação e classificação. In: _. Para compreensão histórica da infância. Belo Horizonte: Autêntica, 2007. p. 185-197.

MACHADO, E. R. O desenvolvimento da Pedagogia Social sob a perspectiva comparada: o estágio atual no Brasil e Espanha. Tese (Doutorado em Educação) Faculdade de Educação da Universidade de São Paulo, SP, 2014

\section{A constituição da Pedagogia Social}

na realidade educacional brasileira. Dissertação (Mestrado em Educação) Universidade Federal de Santa Catarina, SC, 2010.

MARCILIO, M. L. A roda dos expostos e a criança abandonada no Brasil colonial: 17261950. In: FREITAS. M. (Org.) História social da infância no Brasil. São Paulo: Cortez, 1997. p. 51-76.

MINAYO, M. C. S.; CRUZ NETO, O. DESLANDES, S. F.; GOMES, R. Pesquisa social: teoria, método e criatividade. Petrópolis: Vozes, 1999.

OLIVEIRA, S. C. R. Quero voltar para casa: o trabalho em rede e a garantia do direito à convivência familiar e comunitária para crianças e adolescentes que vivem em abrigos. São Paulo: AASPTJ - SP, 2007.

OÑA, J. M. El educador social: un profesional de la educación en contacto con la infancia. Revista de Educación Social, Espanha, n. 4, setembro, 2005. Disponível em: < http:// www.eduso.net $/$ res/?b=7\&c $=64 \& n=177>$. Acesso em: 4 ago. 2017.

PAIVA, J. S. de. Caminhos do Educador Social no Brasil. Jundiaí: Paco, 2015.

PAULA, E. C. L. de O trabalho do (a) educador (a) social nas entidades de acolhimento institucional de crianças e 
adolescentes na cidade de Ponta Grossa - PR. Ponta Grossa, 2015, 90 f. Trabalho de Conclusão de Curso (Graduação em Pedagogia) - Universidade Estadual de Ponta Grossa, Ponta Grossa, 2015.

PAULA, E. C. L. de; MACHADO, E. R. A Pedagogia Social na Educação: análise de perspectivas de formação e atuação dos educadores no Brasil. In: CONGRESSO INTERNACIONAL DE PEDAGOGIA SOCIAL, 2., 2008, São Paulo. Anais eletrônicos... São Paulo: Faculdade de Educação da Universidade de São Paulo, Disponível em: <http://www.proceedings. scielo.br/scielo.php?pid=MSC0000000092 008000100005\&script=sci_arttext.> Acesso em: 20 Mai. 2016.

POLETTO, L. B. A (des) qualificação da infância: a história do Brasil na assistência dos jovens. In: IX ANPED SUL 2012 - SEMINÁRIO DE PESQUISA EM EDUCAÇÃO DA REGIÃO SUL, 9., 2012, Caxias do Sul. Anais eletrônicos... Caxias do Sul: IX ANPED SUL, 2012. Disponível em: <http://www.ucs.br/etc/conferencias/ index.php/anpedsul/9anpedsul/paper/ viewFile/1953/329>. Acesso em: 29 Jun. 2016.

QUINTEIRO, J. Sobre a emergência de uma sociologia da infância: contribuições para o debate. Perspectiva. Florianópolis, v.20, n. Especial, p. 137-162, jul.-dez., 2002. Disponível em: <https://periodicos. ufsc.br/index.php/perspectiva/article/ viewFile/10282/9553>. Acesso em: 20 mai 2016.

SANTANA, D. R. Infância e educação: a histórica construção do direito das crianças. Revista HISTEDBR On-line, Campinas, $\mathrm{n}^{\circ}$ 60, p. 230-245, dezembro, 2014.

SANTOS, A. M. A. dos. Acolhimento institucional de crianças e adolescentes: mudanças na História brasileira. Disponível em: $\quad<$ http://www.cress-mg.org.br/ arquivos/simposio/ACOLHIMENTO\%20 I N S T I T U C I O N A L \% 20 D E \% 20 C R I A N \% C $3 \% 87$ A S \% 20 E \% 20 A D O L E S C E N T E S \% 20 M UD A N \% C $3 \% 87$ A S \% 20 N A \% 20 HIST\%C3\%93RIA\%20BRASILEIRA. pdf.> Acesso em: 15 jun. 2016.

SOUSA, L. M. de. Sentidos sobre infância e desenvolvimento produzidos por educadores de abrigo. 2010, $146 f$. Dissertação (Mestrado em Psicologia) Universidade Federal de Pernambuco, PE, 2010.

TOLEDANO, L. Infancia en riesgo social... ¿De quién hablamos? Revista de Educación Social, Espanha, n. 4, setembro, 2005. Disponível em: < http://www.eduso. net $/ \mathrm{res} / \mathrm{?b}=7 \& \mathrm{c}=54 \& \mathrm{n}=157>$. Acesso em: Acesso em 11 ago. 2017.

WÜRTH, T. Pestalozzi e a pedagogia social. Canoas: Edição de Instituto Pestalozzi de Canoas, 1971. 